\title{
Studi Perencanaan Simpang Koordinasi JI. Dr. Soetomo - JI. RA. Kartini - Jl. Pandegiling di Kota Surabaya
}

\section{Coordination Intersection Planning Study JI. Dr. Soetomo - JI. RA. Kartini - Jl. Pandegiling in the city of Surabaya}

\author{
Anita Susanti $^{1}$, R Endro Wibisono², Ardy Ferdianto ${ }^{3}$ \\ ${ }^{1}$ Jurusan Teknik Sipil, Fakultas Teknik, Universitas Negeri Surabaya, Jln. Ketintang Surabaya. Email : \\ anitasusanti@unesa.ac.id \\ ${ }^{2}$ Jurusan Teknik Sipil, Fakultas Teknik, Universitas Negeri Surabaya, Jln. Ketintang Surabaya. Email : \\ endrowibisono@unesa.ac.id \\ ${ }^{3}$ Jurusan Teknik Sipil, Fakultas Teknik, Universitas Negeri Surabaya, Jln. Ketintang Surabaya. Email : \\ ardiferdianto81@gmail.com
}

\begin{abstract}
Abstrak
Permasalahan persimpangan terjadi pada beberapa ruas jalan yang memiliki banyak persimpangan, ditambah dengan jarak antar simpang yang pendek. Permasalahan yang terkadang terjadi adalah kendaraan harus berhenti pada tiap simpang karena mendapat sinyal merah. Tujuan dari penelitian ini adalah mengetahui hasil rekayasa waktu siklus pada setiap lengan simpang yang menghubungkan Jl. Dr. Soetomo, Jl. RA. Kartini dan Jl. Pandegiling. Untuk mengetahui koordinasi antar simpang empat Jl. Dr. Soetomo dengan simpang Jl. RA Kartini dan simpang Jl. Pandegiling yang selama ini mengakibatkan tundaan yang panjang di Jalan Raya Darmo. Metode analisis data menggunkan metode analisis perhitungan yaitu dengan melakukan perhitungan analisis kinerja pada simpang koordinasi pada ruas Jl. Dr. Soetomo-Jl. RA. Kartini-Jl. Raya Pandegiling baik pada kondisi eksisting ataupun setelah dilakukan rekayasa lalu lintas. Semua perhitungan yang dilakukan mengacu pada Manual Kapasitas Jalan Indonesia (MKJI) tahun 1997. Ketiga simpang yang berada pada ruas jalan Raya Darmo yaitu simpang Dr. Soetomo, simpang RA. Kartini, dan simpang Pandegiling derajat kejenuhan (DS) 1,104, panjang antrian (QL) 832 meter, dan tundaan (Delay) 325 detik. Setelah dilakukannya perencanaan ke empat maka nilai rata-rata simpang untuk DS turun menjadi 0,857, QL turun menjadi 353 meter dan tundaan turun menjadi 75 detik. Nilai offset pada simpang 1 dan 2 ialah 24 detik, pada simpang 2 dan 3 ialah 27 detik, dan pada simpang 1 dan 3 ialah 51. Untuk bendwidth didapat 170 detik hijau pada setiap simpang.
\end{abstract}

Kata Kunci: Koordinasi simpang bersinyal; waktu siklus; detik hijau; derajat kejenuhan

\begin{abstract}
Intersection problems occur on several roads that have many intersections, plus short distances between intersections. The problem that sometimes occurs is that vehicles have to stop at each intersection because they get a red signal. The purpose of this study is to determine the results of the cycle time engineering at each intersection arm that connects Jl. Dr. Soetomo, Jl. RA. Kartini and Jl. Pandegiling. To find out the coordination between the four intersections of Jl. Dr. Soetomo with the intersection of Jl. RA Kartini and the intersection of Jl. Pandegiling which has resulted in long delays on Jalan Raya Darmo. The data analysis method uses the calculation analysis method, namely by calculating the performance analysis at the coordination intersection at Jl. Dr. Soetomo - Jl. RA. Kartini - Jl. Raya Pandegiling either in existing conditions or after traffic engineering. All calculations carried out refer to the Indonesian Road Capacity Manual (MKJI) 1997. The three intersections on Raya Darmo road are the Dr. Soetomo, the RA intersection. Kartini, and the Pandegiling intersection, the degree of saturation (DS) is 1.104, the queue length $(Q L)$ is 832 meters, and the delay (Delay) is 325 seconds. After doing the fourth planning, the average intersection value for DS dropped to 0.857, QL fell to 353 meters and Delay decreased to 75 seconds. The offset value at intersections 1 and 2 is 24 seconds, at intersections 2 and 3 is 27 seconds, and at intersections 1 and 3 is 51. For bendwidth we get 170 seconds green at each intersection.
\end{abstract}

Keywords: Coordination of signaled intersections; cycle time; green time; degree of saturation 


\section{PENDAHULUAN}

Transportasi merupakan suatu kebutuhan yang sangat vital pada suatu perkembangan suatu negara, dimana negara tersebut tidak dapat berkembang tanpa ditopang dengan adanya dunia transportasi sehingga menghasilkan suatu pertumbuhan perekonomian yang merata pada negara tersebut. Tujuan transportasi adalah untuk mewujudkan penyelenggaraan transportasi yang selamat, aman, cepat, lancar, tertib dan nyaman serta berdaya guna dengan biaya yang terjangkau oleh daya beli masyarakat, menunjang pemerataan pertumbuhan dan stabilitas sebagai pendorong, penggerak dan penunjang pembangunan nasional serta mempererat hubungan antar bangsa (Warpani 1990). Transportasi darat merupakan bagian transportasi yang menjadi urat nadi perekonomian suatu daerah, dimana berkaitan erat dengan kegiatan sehari-hari masyarakat perkotaan. Lalu lintas dan jaringan jalan diperkotaan yang semakin padat dan memunculkan titik temu antara jaringan jalan ataupun biasa disebut dengan persimpangan menjadi salah satu faktor terjadinya kemacetan lalu lintas di kota kota besar di Indonesia.

Persimpangan pun menjadi salah satu bagian yang harus diperhatikan dalam rangka melancarkan arus transportasi di perkotaan. Oleh karena itu, keberadaanya harus dikelola sedemikian rupa sehingga didapatkan kelancaran pergerakan yang diharapkan. Cara yang dapat digunakan adalah dengan mengatur pergerakan yang terjadi pada persimpangan. Adapun fasilitas yang dapat difungsikan adalah lampu lalu-lintas (traffic light).

Permasalahan tersebut terjadi pada beberapa ruas jalan yang memiliki banyak persimpangan, ditambah dengan jarak antar simpang yang pendek. Permasalahan yang terkadang terjadi adalah kendaraan harus berhenti pada tiap simpang karena mendapat sinyal merah. Tentu saja hal ini menimbulkan ketidak nyamanan pengendara, disamping lamanya tundaan yang terjadi.

Dalam penelitian ini terdapat dua rumusan masalah, yaitu berapa hasil rekayasa waktu siklus pada setiap lengan simpang yang menghubungkan Jl. Dr. Soetomo, Jl. RA. Kartini dan Jl. Pandegiling ?; bagaimanakah mengkoordinasikan simpang empat J1. Dr. Soetomo dengan simpang Jl. RA Kartini dan simpang Jl. Pandegiling?

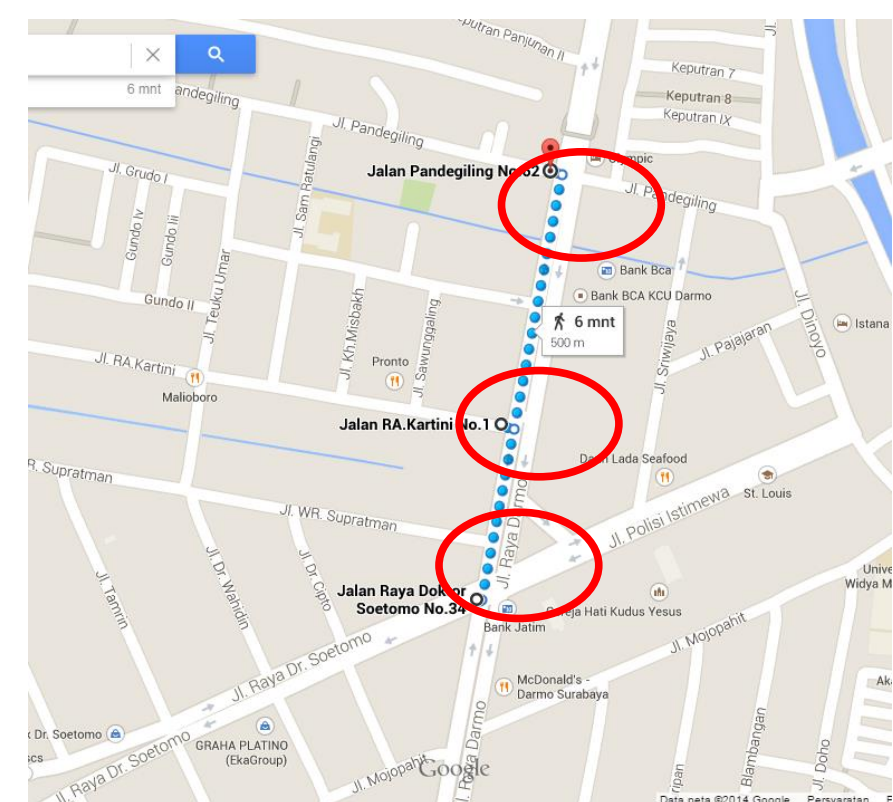

Gambar 1. Gambar Map simpang koordinasi ruas $\mathrm{J} J \mathrm{I}^{\circ}$

Dr. Soetomo, Jl. RA kartini, dan Jl. Pandegiling. Sumber : Google Maps 2014

Berdasarkan gambar 1 terdapat tiga simpang yang memotong jalan Raya Darmo, ketiga simpang tersebut ialah simpang jalan Dr. Soetomo, simpang jalan RA. Kartini, dan simpang jalan Pandegiling yang posisinya saling berdekatan. Pada kondisi eksisting dilapangan, jarak antara simpang Dr. Soetomo dengan simpang jalan RA. Kartini berjarak $200 \mathrm{~m}$, sedangkan jarak dari simpang jalan RA. Kartini dengan simpang ruas Jl. Pandegiling berjarak $300 \mathrm{~m}$ dengan waktu siklus pada simpang Dr. seotomo sisi selatan ialah 190 detik, pada simpang RA kartini waktu siklus simpang 180 detik, serta pada simpang pandegiling waktu siklus 160 detik. Berdasarkan hasil perhitungan yang dilakukan pada survei pendahuluan, ketiga simpang yang memotong jalan Raya Darmo memiliki derajat kejenuhan yang tinggi, dimana pada simpang Dr. soetomo 1,0194, pada simpang RA kartini 1,196, dan pada simpang pandegiling 0,995 .

Tujuan dari penelitian ini adalah mengetahui hasil rekayasa waktu siklus pada setiap lengan simpang yang menghubungkan Jl. Dr. Soetomo, Jl. RA. Kartini dan Jl. Pandegiling. Untuk mengetahui koordinasi antar simpang empat Jl. Dr. Soetomo dengan simpang Jl. RA Kartini dan simpang Jl. Pandegiling yang selama ini mengakibatkan tundaan yang panjang di Jalan Raya Darmo. 


\section{METODE PENELITIAN}

Untuk mendapatkan cycle time baru, akan dilakukan beberapa perencanaan. Hal ini dilakukan untuk mengetahui karakteristik kinerja simpang yang didasarkan pada cycle time yang berbeda-beda. Kinerja terbaik akan dipilih, untuk selanjutnya cycle time terpilih digunakan dalam mengkoordinasikan simpang. Dalam kasus ini sedikitnya akan dilakukan lima perencanaan, yaitu perencanaan waktu siklus Simpang I, kemudian ketiga simpang lainnya direncanakan dengan waktu siklus dari Simpang I. Perencanaan waktu siklus Simpang II, kemudian ketiga simpang lainnya direncanakan dengan waktu siklus dari Simpang II. Perencanaan waktu siklus Simpang III, kemudian ketiga simpang lainnya direncanakan dengan waktu siklus dari Simpang III.

Dari waktu siklus masing-masing simpang, diambil rata-rata dari keempatnya dan waktu siklus rata-rata tersebut direncanakan pada semua simpang. Perencanaan terbaik akan dipilih menggunakan metode pembobotan pada tiga jenis kinerja simpang, yaitu Derajat Kejenuhan (DS), Panjang Antrian (QL), dan Tundaan (Delay). Adapun pembobotannya adalah 0,5 untuk DS, 0,2 untuk QL, dan 0,3 untuk Delay. Nilai ketiga kinerja diambil dari rata-rata kinerja pada arus maksimum atau arus-arus besar (mayor) pada setiap simpangnya. Kinerja dengan nilai terkecil atau kinerja terbaik akan mendapat prioritas utama yang ditandai oleh nominal angka kecil. Hasil pemilihan merupakan jumlah bobot ketiga kinerja setelah dikalikan dengan angka prioritas. Perencanaan terpilih merupakan perencanaan yang memiliki nilai hasil pemilihan yang terkecil.

Metode analisis data menggunkan metode analisis perhitungan yaitu dengan melakukan perhitungan analisis kinerja pada simpang koordinasi pada ruas Jl. Dr. Soetomo - Jl. RA. Kartini - Jl. Raya Pandegiling baik pada kondisi eksisting ataupun setelah dilakukan rekayasa lalu lintas. Semua perhitungan yang dilakukan mengacu pada Manual Kapasitas Jalan Indonesia (MKJI) tahun 1997.

\section{HASIL DAN PEMBAHASAN}

Kondisi eksisting merupakan suatu kondisi yang terjadi di lapangan dimana potret suatu lokasi studi yang murni, tanpa ada pengolahan ataupun perencanaan terhadap kondisi yang sudah ada. Kondisi eksisting meliputi inventarisasi, tata guna lahan, keadaan, kondisi, dan potret permasalahan yang terjadi di suatu lokasi studi. Dalam studi perencanaan simpang koordinasi pada ruas jalan Raya Darmo terdapat tiga persimpangan yang memotong arus lalu lintas di ruas jalan tersebut, meliputi persimpangan jalan Dr. Soetomo, persimpangan jalan RA. Kartini, dan persimpangan jalan Pandegiling.

Pada simpang Dr. Soetomo semua ruas yang menuju simpang ini memiliki lingkungan komersial dengan hambatan yang tinggi, dikarenakan pada semua ruas yang mendekati mulut simpang berupa kawasan CBD dan juga terdapat sekolah, dimana pada jam sibuk keluar masuk kendaraan sangat mempengaruhi kinerja dari simpang itu sendiri. Pada simpang ini memiliki satu pendekat LTOR, yaitu pada sisi pendekat Timur yang menuju ke arah selatan.

Pada simpang RA. Kartini lingkungan dari arah utara-selatan memiliki lingkungan komersial, dimana masih di wilayah ruas jalan raya Darmo, dan pada sisi barat dari arah RA. Kartini berupa lingkungan (RES) permukiman dengan hambatan rendah, dengan LTOR menuju arah Jl. Raya Darmo dan pada jam tertentu diberlakukan pemindahan arus dari arah RA. Kartini menuju Jl. Raya Darmo.

Pada simpang Pandegiling sisi utara-selatan tetap memiliki lingkungan komersial dan pada sisi barattimur memiliki hambatan samping. Pada sisi barat terdapat PKL (Pedagang kaki lima) yang memenuhi sepanjang jalan, sedangkan pada sisi timur terdapat kawasan pasar yang juga memakan badan jalan Pandegiling. Pada simpang ini tidak ada LTOR dan juga belok kanan (Right turn) sehingga hanya memiliki 2 fase.

Waktu siklus adalah urutan lengkap dari indikasi sinyal (antara dua saat permulaan hijau yang berurutan di dalam pendekat yang sama). waktu siklus terdiri dari beberapa waktu sinyal, diantaranya waktu sinyal merah, kuning, dan hijau dan kembali lagi ke waktu sinyal merah. Dalam simpang koordinasi waktu siklus sangat penting dalam pengkoordinasian antar simpang, sebagai acuan untuk perhitungan waktu sinyal diantara ketiga simpang yang akan dikoordinasikan. Waktu siklus pada simpang Dr. Soetomo, RA. Kartini, dan Pandegiling memiliki waktu siklus yang berbeda oleh karena itu ketiga simpang tersebut belum dikatakan sudah terkoordinasi. Berikut tabel waktu siklus yang ada pada ketiga simpang tersebut. 
Tabel 1. Data waktu siklus simpang Dr. Soetomo

\begin{tabular}{|c|c|c|c|c|c|}
\hline \multirow{2}{*}{ Pendekat } & \multicolumn{5}{|c|}{ Waktu siklus } \\
\cline { 2 - 6 } & Merah & Kuning & Hijau & All red & Jumlah \\
\hline U & 50 & 3 & 135 & 2 & 190 \\
\hline S & 100 & 3 & 85 & 2 & 190 \\
\hline T & 140 & 3 & 45 & 2 & 190 \\
\hline B & 140 & 3 & 45 & 2 & 190 \\
\hline
\end{tabular}

Sumber : Perhitungan MKJI

Pada tabel diatas menunjukan waktu siklus 190 detik dengan waktu all red 2 detik dan kuning 3 detik pada semua pendekat. Waktu hijau pada pendekat utara ialah 135 detik dengan 2 fase pergerakan. Sedangkan pada pendekat timur dan barat waktu sinyal merah 140 detik dengan 2 fase pergerakan tunggu.

Tabel 2. Data waktu siklus simpang RA. Kartini

\begin{tabular}{|c|c|c|c|c|c|}
\hline \multirow{2}{*}{ Pendekat } & \multicolumn{5}{|c|}{ Waktu siklus } \\
\cline { 2 - 6 } & Merah & Kuning & Hijau & All red & Jumlah \\
\hline U & 120 & 3 & 54 & 3 & 180 \\
\hline S & 60 & 3 & 114 & 3 & 180 \\
\hline B & \multicolumn{6}{|c|}{ Tanpa Apill } \\
\hline
\end{tabular}

Sumber : Perhitungan MKJI

Pada tabel diatas menunjukan waktu siklus 180 detik dengan all red 3 detik dan waktu kuning 3 detik pada semua pendekat simpang RA. Kartini. Pada pendekat barat tidak menggunakan Apill dikarenakan volume yang masuk menuju jalan raya darmo dialihkan menuju persimpangan sesudah simpang RA. Kartini, untuk menguraikan volume yang masuk ke arah jalan raya darmo.

Tabel 4.9 Data waktu siklus simpang Pandegiling

\begin{tabular}{|c|c|c|c|c|c|}
\hline \multirow{2}{*}{ Pendekat } & \multicolumn{5}{|c|}{ Waktu siklus } \\
\cline { 2 - 6 } & Merah & Kuning & Hijau & All red & Jumlah \\
\hline U & 50 & 3 & 104 & 3 & 160 \\
\hline S & 50 & 3 & 104 & 3 & 160 \\
\hline T & 110 & 3 & 44 & 3 & 160 \\
\hline B & 110 & 3 & 44 & 3 & 160 \\
\hline
\end{tabular}

Sumber : Perhitungan MKJI

Pada tabel diatas waktu siklus menunjukan 160 detik, dengan all red 3 detik, dan waktu sinyal kuning 3 detik. Pada simpang pandegiling hanya memiliki 2 fase. Fase merupakan sebuah pergerakan dari keseluruan pada simpang secara bergantian, dimana tiap simpang yang dikendalikan oleh APILL memiliki beberapa fase diantaranya ialah dua fase, tiga fase, empat fase ataupun lima fase. Fase dalam sebuah persimpangan bertujuan untuk mengurangi pergerakan lalu lintas yang berlawanan dalam masing masing lengan. Berikut fase yang ada pada simpang jalan Dr. Soetomo, RA Kartini dan Pandegiling.

\section{Analisis Kinerja Simpang Kondisi Eksisting}

Analisis dilakukan menggunakan perhitungan Manual Kapasitas Jalan Indonesia (MKJI). Proses analisis dilakukan pada setiap simpang di lokasi studi, sebelum nantinya akan dilakukan proses perencanaan simpang koordinasi dari ketiga simpang tersebut. Hasil perhitungan awal kinerja simpang kondisi eksisting, dimana setiap lengan simpang dilakukan perhitungan dengan kondisi waktu sinyal, jumlah kendaraan, agar nantinya dapat diketahui berapa kinerja masing-masing dari ketiga simpang, yang digunakan sebagai acuan perhitungan perencanaan simpang koordinasi.

Rombongan pletoon (arus kendaraan) pada ruas mayor terbesar dimulai dari arah selatan, sebelum masuk simpang Dr. Soetomo sudah memiliki Derajat kejenuhan yang tinggi yaitu 1,094 dengan panjang antrian $778 \mathrm{~m}$, setelah masuk pada simpang kedua yaitu simpang RA. Kartini Derajat kejenuhan (DS) meningkat pada 1,143 dan memiliki panjang antrian yang tinggi yaitu $1.467 \mathrm{~m}$. Masuk pada simpang ketiga yaitu simpang pandegiling derajat kejenuhan mencapai 1,153 dan panjang memiliki panjang antrian $1.507 \mathrm{~m}$.

Rombongan pletoon pada ruas mayor dari arah utara, dimulai dari masuk simpang pandegiling dengan derajat kejenuhan yang tinggi yaitu 1,180 dengan panjang antrian mencapai $1.829 \mathrm{~m}$ dari ruas jalan urip sumoharjo, masuk pada simpang RA. Kartini derajat kejenuhan meningkat menjadi 1,243 dengan panjang antrian $315 \mathrm{~m}$, disini panjang antrian mengalami penurunan dikarenakan hanya satu lajur yang akan memulai masuk simpang RA. Kartini, masuk pada simpang ketiga simpang Dr Soetomo derajat kejenuhan menurun menjadi 0,884 , dengan panjang antrian $466 \mathrm{~m}$, disini DS dan panjang antrian menurun dikarenakan lebar pendekat masuk yang besar dan arus belok kiri di alihkan sebelum masuk simpang, sehingga tidak membebani simpang Dr. Soetomo.

\section{Kinerja Perencanaan I}

Pada perencanaan ini, dimluai dengan manajemen lalu lintas dari setiap simpang yang akan dikoordinasikan, dengan perhitungan waktu hijau, merah, dan kuning, nantinya perencanaan waktu siklus baru untuk semua simpang akan mengacu pada perencanaan waktu siklus simpang pertama. Perencanaan pertama dilakukan proses manajemen lalu lintas dengan mengubah waktu siklus dan waktu perencanaan pada waktu hijau, merah, dan kuning. 
Serta menganalisa fase - fase sebelumnya yang masih belum efisien, seperti pada simpang Dr. Soetomo.

Pada perencanaan eksisitng fase 3, laju arus kendaraan belok kiri pada pendekat barat, seharusnya tidak berhenti karena disitu tidak terjadi pertemuan antara arus pendekat lainya, dan untuk waktu hijaunya mengikuti waktu hijau pada fase tiga. Selanjutnya fase dua diubah menjadi fase tiga, dan fase tiga menjadi fase dua, agar waktu hijau pada pendekat barat memiliki waktu hijau lebih lama serta langsung berlanjut kepada fase tiga.

Setelah dilakukannya manajemen lalu lintas pada perencanaan 1 , perubahan waktu siklus dilakukan untuk mendapat hasil perhitungan yang meningkatkan kinerja dari simpang-simpang pada lokasi studi perubahan waktu siklus eksisting dari rekap awal berubah menjadi 210 detik, dan disamakan pada semua simpang. Pada pendekat barat setelah dilakukannya perubahan fase dan pergerakan, waktu hijaunya mengalami peningkatan menjadi 100 detik yang didapat dari waktu hijau pada fase 2 dan 3, sehingga derajat kejenuhan dari pendekat barat mengalami penurunan yang signifikan, menjadi 0,606. Dan juga pada perencanaan in, semua pendekat mengalami penurunan nilai derajat kejenuhan, namun nilai DS dirasa masih tinggi dan perlu perencanaan ulang.

\section{Kinerja Perencanaan II}

Pada perencanaan ini perhitungan kinerja simpang mementingkan pendekat pada jalan mayor, atau jalan utama yaitu jalan Raya Darmo, untuk meminimalkan derajat kejenuhan (DS), yang membebani pada ruas jalan tersebut. Namun tidak serta merta menghiraukan jalan minor, tetap perencanaan bertujuan untuk meminimalisir nilai DS yang tinggi pada setiap pendekat yang berada di lokasi studi.

Waktu siklus berubah menjadi 230 detik, dan perubahan pada waktu hijau, dan merah. Terlihat pada tebel simpang Dr. Soetomo pendekat selatan mengalami penurunan dari pererncanaan pertama 1,082 menjadi 0,979. Pada pendekat-pendekat lainnya mengalami penurunan rata-rata DS, waktu delay serta panjang antrian. Namun pada pendekat utara simpang kartini mengalami peningkatan derajat kejenuhan (DS), dikarenakan perhitungan lebih mengoptimalkan pada penurunan derajat kejenuhan (DS) pada pendekat selatan. Pada perencanaan kedua kinerja simpang masih belum optimal dikarenakan nilai rata-rata kinerja masih tinggi, dan perlu perencanaan selanjuntya.

\section{Kinerja Perencanaan III}

Pada sisi barat dan timur simpang Dr. Soetomo proses pelebaran jalan dimulai dengan mengurangu jumlah median yang dianggap terlalu lebar, dari lebar median $6,8 \mathrm{~m}$ menjadi $5 \mathrm{~m}$, untuk kedua sisi pendekat masuk, sedangkan pada simpang Pandegiling lebar jalan pada sisi selatan utara dilakukan dengan mengurangi lebar dari trotoar, pada sisi timur dan barat pelbaran jalan dengan pelebaran lahan sebelah jalan karena dianggap terlalu kecil. Dari analisis perhitungan didapatkan didapatkan nilai derajat kejenuhan (DS) yang lebih rendah dibandingkan perencanaan kedua dan pertama, namun waktu siklus direncanakan besar yaitu 250 detik, agar semua pendekat dapat memiliki kinerja yang baik. Pendistribusian waktu hijau pada setiap pendekat sangatlah penting dilakukan karena volume antara jalan mayor dan minor perbedaannya tak sebegitu besar. Simpang Dr. Soetomo mengalami penurunan menjadi 0,783 termasuk kategori level of service (LOS) D. Namun pada simpang RA. Kartini dan Pandegiling masih memiliki rata-rata derajat kejenuhan (DS) yang tinggi yaitu 0,93 dan 0,894 dimana termasuk dalam kategori LOS E.

\section{Kinerja Perencanaan IV}

Pada perencanaan ini, proses perhitungan waktu hijau dan merah mengacu pada waktu jam puncak pada persimpangan seperti, pada puncak pagi dan sore, nantinya akan diberlakukan fleksibel lampu lalu lintas, dimana nilai waktu hijau dan merah pada puncak pagi dan sore akan dilakukan bergantian, jadi dalam lampu lalu lintas akan direncanakan 2 perencanaan waktu hijau dan merah yaitu perencanaan pagi dan sore karena pada saat yang berbeda nilai volume lalu lintas pada puncak pagi dan sore memiliki perbedaan yang signifikan. Untuk perencanaan waktu persimpangan pada perencanaan keempat pada puncak sore, dilakukan perencanaan yang sama dengan waktu sore pada perencanaan ketiga, dikarenakan perencanaan ini hanya menyempurnakan dengan menambahkan perencanaan pagi. Berikut merupakan perencanaan waktu persimpangan keempat. 
Tabel 3. Tabel perencanaan waktu pada simpang

\begin{tabular}{|c|c|c|c|c|c|c|}
\hline \multirow{2}{*}{ Pendekat } & \multicolumn{7}{|c|}{ Wr. Soetomo puncak pagi } \\
\cline { 2 - 7 } & Hijau & Merah & Kuning & All red & LTI & Jumlah \\
\hline U & 185 & 50 & 3 & 2 & 15 & 250 \\
\hline S & 170 & 65 & 3 & 2 & 15 & 250 \\
\hline T & 50 & 185 & 3 & 2 & 15 & 250 \\
\hline B & 65 & 170 & 3 & 2 & 15 & 250 \\
\hline
\end{tabular}

Sumber: Perhitungan MKJI

Tabel 4. Tabel perencanaan waktu pada simpang RA. Kartini puncak pagi

\begin{tabular}{|c|c|c|c|c|c|c|}
\hline \multirow{2}{*}{ Pendekat } & \multicolumn{7}{|c|}{ Waktu siklus } \\
\cline { 2 - 7 } & Hijau & Merah & Kuning & All red & LTI & Jumlah \\
\hline U & 44 & 194 & 3 & 3 & 12 & 250 \\
\hline S & 194 & 44 & 3 & 3 & 12 & 250 \\
\hline B & \multicolumn{7}{|c|}{ Tanpa Apill } \\
\hline
\end{tabular}

Sumber: Perhitungan MKJI

Tabel 5. Tabel perencanaan waktu pada simpang Pandegiling puncak pagi

\begin{tabular}{|c|c|c|c|c|c|c|}
\hline \multirow{2}{*}{ Pendekat } & \multicolumn{7}{|c|}{ Waktu siklus } \\
\cline { 2 - 7 } & Hijau & Merah & Kuning & All red & LTI & Jumlah \\
\hline U & 194 & 44 & 3 & 3 & 12 & 250 \\
\hline S & 194 & 44 & 3 & 3 & 12 & 250 \\
\hline T & 44 & 194 & 3 & 3 & 12 & 250 \\
\hline B & 44 & 194 & 3 & 3 & 12 & 250 \\
\hline
\end{tabular}

Sumber: Perhitungan MKJI

DS pada pendekat selatan simpang Dr. Soetomo mengalami penurunan yang signifikan yaitu dari DS eksisting 1,094 menjadi 0,785, dan pada pendekat barat kondisi eksisting dengan DS 1,218 turun menjadi 0,651 sehingga rata-rata dari simpang Dr. Soetomo menjadi 0,783 dan nilai rata-rata panjang antrian dan waktu tunggu dari $685 \mathrm{~m}$ menjadi $350 \mathrm{~m}$ dan nilai tundaan dari 341 menjadi 61 detik. Pada simpang selanjutnya di simpang RA. Kartini dan Pandegiling nilai DS menjadi semakin besar mencapai 1,235 dan 1,231 dari sebelumnya pada nilai 1,143 dan 1,153 . Oleh karenanya proses perencanaan keempat memberlakukan perhitungan puncak pagi dan sore. Untuk mengetahui berapa nilai volume pada puncak pagi dan sore, lihat tabel pada volume lalu lintas pada puncak pagi dan sore ataupun bisa dilihat pada lembar lampiran. Berikut merupakan tabel perhitungan pada perencanaan keempat puncak pagi dan sore.

\section{Penilaian Kinerja Perencanaan Terbaik}

Perencanaan keempat merupakan nilai yang terbaik dari sebelumnya dikarenakan pada perencanaan ini, nilai rata-rata derajat kejenuhan (DS) mampu menurun menjadi 0,857 , waktu tunggu 353,18 dan juga waktu tunggu 74,53, maka yang akan menjadi acuan untuk simpang koordinasi ialah perencanaan keempat, dimana menggunakan fleksibel lampu lalu lintas, artinya antara waktu hijau, dan merah pagi dan sore berbeda.

\section{Koordinasi Sinyal Antar Simpang}

Koordinasi sinyal dilakukan dengan menggunakan waktu siklus dan waktu hijau dari perencanaan dengan kinerja terbaik. Setelah melalui proses pembobotan tiap kinerja pada semua perencanaan, terpilihlah perencanaan keempat, karena memiliki kinerja simpang rata-rata yang lebih baik daripada perencanaan lainnya. Dalam perencanaan ini, digunakan kecepatan maksimum dalam kota sesuai dengan peraturan Dirjen Perhubungan Darat, sebesar $40 \mathrm{~km} / \mathrm{jam}$. Kecepatan rencana ini dipilih karena pertimbangan bahwa dengan kecepatan lambat maka akan didapat waktu offset yang cukup panjang, sehingga kendaraan terakhir dalam platoon masih memiliki kesempatan untuk mendapat sinyal hijau, jadi tidak perlu menunggu dalam sinyal merah selama satu siklus lagi. Sedangkan kendaraan yang terlalu cepat hanya cukup menunggu waktu hijau dalam beberapa detik saja. Dengan kecepatan yang sama, maka waktu platoon untuk berjalan dari Utara ke Selatan dan sebaliknya juga sama. berikut waktu tempuh dari utara ke selatan dan selatan ke utara.

Waktu tempuh 45 detik digunakan sebagai waktu offset untuk menggambarkan lintasan pergerakan platoon pada diagram koordinasi. Setelah lintasan didapat, maka waktu hijau tiap simpangnya menyesuaikan dengan lintasan dengan menggeser secara horizontal.

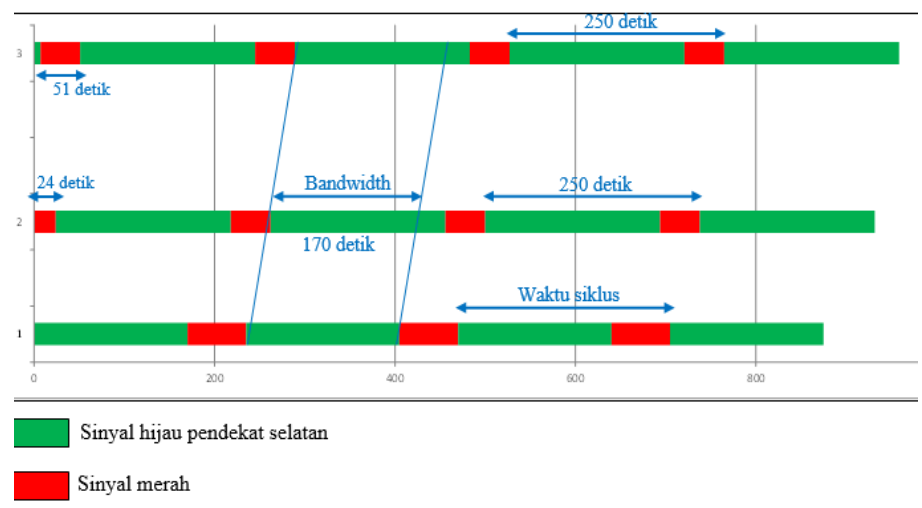

Gambar 2. Diagram aliran pletoon rencanaa koordinasi puncak pagi.

Proteksi/Juni 2021 Volume 3 No. 1 
Berdasarkan gambar diagram koordinasi puncak pagi diatas, dapat dilihat bandwidth penuh pada waktu hijau simpang pertama yaitu 170 detik, dikarenakan pada simpang kedua dan ketiga memiliki waktu hijau yang lebih panjang dibandingkan waktu hijau pertama, berikut perhitungan nilai waktu bandwidth puncak pagi pada perencanaan koordinasi diatas.

Waktu tempuh + acc kendaraan dari kec. $0=18+6$ $=24$ detik. Dari waktu merah 44 detik - waktu tempuh 1 ke 2 yaitu 24 detik $=20$ detik. Berdasarkan uraian di atas, waktu tempuh kendaraan dari simpang pertama ke simpang kedua yaitu 24 detik, awal pletoon (rombongan kendaraan) masuk simpang kedua, jadi awal waktu lalu lintas pada simpang kedua 24 detik waktu merah, menunggu 20 detik dari waktu merah pada simpang kedua 44, agar dapat memulai waktu merah 24 detik sebelum masuk waktu hijau pada lintasan bandwidth.

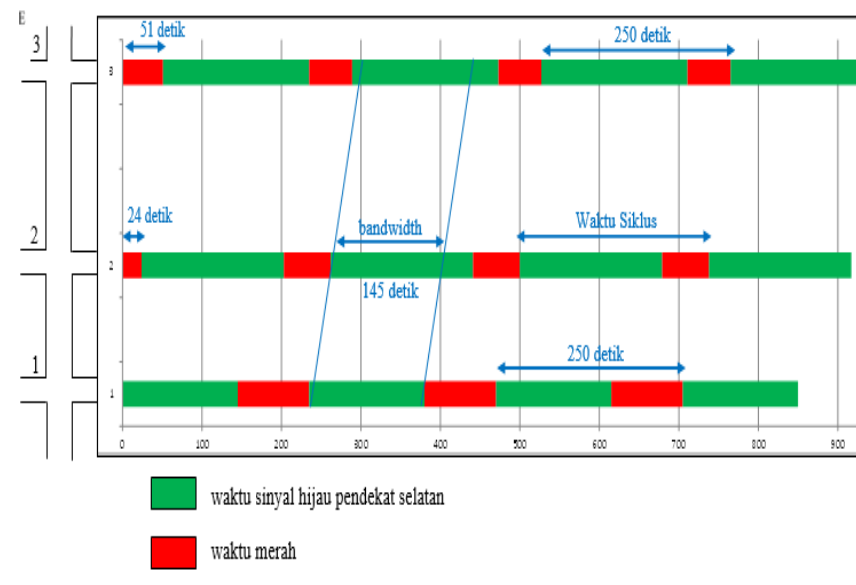

Gambar 3. Diagram aliran pletoon rencanaa koordinasi puncak pagi.

Berdasarkan uraian di atas, waktu tempuh kendaraan dari simpang pertama ke simpang ketiga yaitu 51 detik, awal pletoon (rombongan kendaraan) masuk simpang kedua, jadi awal waktu lalu lintas pada simpang kedua 51 detik waktu merah, menunggu 3 detik dari waktu merah pada simpang kedua 54, agar dapat memulai waktu merah 51 detik sebelum masuk waktu hijau pada lintasan bandwidth simpang ketiga.

Dari gambar tabel diatas didapatkan nilai DS pada perencanaan ditandakan dengan garis merah untuk perencanaan pagi dan garis biru untuk perencanaan sore, maka didapatkan kecepatan rata-rata pada perencanaan pagi ialah $30 \mathrm{~km} / \mathrm{jam}$ dan untuk perencanaan sore $29 \mathrm{~km} / \mathrm{jam}$. Setelah didapat kecepatan eksisitng pada ruas jalan ini kita perhitungkan kembali dengan kecepatan 29 km/jam kita ambil kecepatan terendah karena dijadikan sebagai acuan kemungkinan kecepatan terendah, untuk perhitungannya sebagai berikut. Diketahui jarak dari simpang1 ke simpang 3 adalah $500 \mathrm{~m}$ atau $0,5 \mathrm{~km}$. Kecepatan eksisting berdasarkan nilai $\mathrm{DS}=$ $29 \mathrm{~km} / \mathrm{jam}$. Dari waktu tempuh perhitungan diatas sebesar 68 detik, dengan bandwidth untuk perencanaan pagi 170 detik dan sore 145 detik maka diperkirakan dapat mencover kebutuhan waktu tempuh dari simpang pertama ke simpang ketiga.

\section{KESIMPULAN}

Ketiga simpang yang berada pada ruas jalan Raya Darmo yaitu simpang Dr. Soetomo, simpang RA. Kartini, dan simpang Pandegiling sebelumnya belum terkoordinasi, hal ini dapat dilihat dari waktu siklus eksisting yang berada pada simpang tersebut berbeda-beda dari simpang pertama memiliki waktu siklus 190 detik, pada simpang kedua 180 detik, dan pada simpang ketiga 160 detik.

Dalam proses perencanaan simpang didapat nilai kinerja eksisting rata- rata ketiga simpang derajat kejenuhan (DS) 1,104, panjang antrian (QL) 832 meter, dan tundaan (Delay) 325 detik. Setelah dilakukannya perencanaan ke empat maka nilai ratarata simpang untuk DS turun menjadi 0,857, QL turun menjadi 353 meter dan Delay turun menjadi 75 detik.

Perencanaan koordinasi ketiga simpang tersebut, dilakukan dengan menentukan waktu siklus yang sama terlebih dahulu, selanjutnya akan dilakukan perencanaan dengan menguraikan satu persatu simpang untuk mencari kinerja ideal dari masingmasing simpang. Setelah didapatkan hasil kinerja yang ideal maka dilakukan pembobotan penilaian perencanaan kinerja terbaik, yang nantinya akan digunakan sebagai acuan dalam perencanaan koordinasi simpang.

Hasil diatas digunakan sebagai acuan perencanaan simpang koordinasi, dengan dua perencanaan yaitu pada puncak pagi dan sore, pada perencanaan pagi nilai offset pada simpang 1 dan 2 ialah 24 detik, pada simpang 2 dan 3 ialah 27 detik, dan pada simpang 1 dan 3 ialah 51. Untuk bendwidth didapat 170 detik hijau pada setiap simpang. Sedangkan pada perencanaan sore nilai offset pada setiap simpang sama, perbedaan terdapat pada nilai bandwidth yaitu 145 detik pada perencanaan sore. 


\section{REFERENSI}

Alvinsyah \& Soehodho, S. 1997. Dasar - Dasar Sistem Transportasi, Laboratorium Transportasi Jurusan Sipil Fakultas Teknik Universitas Indonesia, Jakarta.

Arifin, J. \& Fauzi, A.. 1999. Mengupas Tuntas Microsoft Excel. 2000. Penerbit PT. Elex Media Komputindo, Jakarta.

Ananto. Setyabudi. 2002. Koordinasi Simpang Bersinyal Simpang Pingit- Jlagran Cokroaminot. Tugas Akhir. Fakultas Teknik Sipil dan Perencanaan, Universitas Islam Indonesia. Jogjakarta.

Chitra, A.S.2008.Analisis Koordinasi Sinyal Antar Simpang (Studi Kasus Pada Simpang Jl. Merdeka - Jl. RE. Martadinata dan Jl. Merdeka - Jl. Aceh Kota Bandung).Institut Teknologi Bandung.

Direktorat Jenderal Bina Marga. 1997. Manual Kapasitas Jalan Indonesia, Jakarta.
Emal Z. M. 2010. Analisa dan Koordinasi Sinyal antar Simpang pada Ruas Jalan Diponegoro Surabaya. Skripsi Sarjana, Jurusan Teknik Sipil, Institute Teknologi Sepuluh November, Surabaya.

Fitria. Purnayanti. 2013. Koordinasi Simpang Bersinyal Simpang Kentungan-Simpang Monjali, Jurusan Teknik Sipil dan Lingkungan, Fakultas Teknik, Universitas Gajah Mada. Yogyakarta.

Hobbs. F.D. 1995. Perencanaan dan Teknik Lalu Lintas.Yogyakarta:Gadjah Mada University Press.

Iskandar. Abubakar 1993. Menuju Lalu Lintas dan Angkutan Jalan yang Tertib. Penerbit Direktorat Jenderal Perhubungan Darat.

Joni. Hariyanto. 2004. Sistem Pengendalian Lalu Lintas Pada Pertemuan Sebidang. Jurusan Teknik Sipil, Fakultas Teknik, Universitas Sumatera Utara.

Wibisono. E. 2020. “Analisa Dampak Lalu Lintas Jalan Tambak Osowilangun Akibat Pembangunan Teluk Lamong Surabaya," UKaRsT, vol. 4, no. 1, p. 69, 2020, doi: 10.30737/ukarst.v4i1.690. 